1. MBBS, FCPS

Assistant Professor Surgery

Bolan University of Medical \& Health Sciences Quetta.

2. MBBS, FCPS, MRCS, FRCS (Glasgow)

Consultant Surgeon

Muhtarama Shaheed Benazeer Butto Hospital Quetta.

3. MBBS, FCPS

Assistant Professor Surgery

Bolan University of Medical \& Health

Sciences Quetta.

4. MBBS, FCPS

Assistant Professor Surgery Bolan University of Medical \& Health Sciences Quetta.

5. MBBS, FCPS

Assistant Professor Surgery

Bolan University of Medical \& Health Sciences Quetta.

6. MBBS, FCPS

Professor Surgery

Bolan University of Medical \& Health

Sciences Quetta.

Correspondence Address:

Dr. Manzoor Ahmed

Department of Surgery S.U.II

BUMHS

Sandema (Prov) Teaching Hospital

M.A. Jinnah Road Quetta.

drmanzoorbaloch@gmail.com

Article received on:

13/04/2019

Accepted for publication:

05/08/2019

\section{LIGASURE VESSEL SEALING SYSTEM VERSUS CONVENTIONAL TOOLS IN MILLIGAN AND MORGAN HAEMORRHOIDECTOMY: A RANDOMIZED CONTROL TRIAL.}

\author{
Manzoor Ahmed', Mukhtar Mehboob², Fida Ahmed ${ }^{3}$, Saleem Javeed ${ }^{4}$, Abdullah Khan ${ }^{5}$,
} Shoaib Ahmed Qureshi ${ }^{6}$

ABSTRACT... Objectives: To evaluate the efficacy and safety of the LigaSure vessel sealing system in Milligan - Morgan Haemorrhoidectomy and compare to conventional tools. Study Design: Randomized control trial. Setting: Department of surgery Bolan University of Medical and Health Sciences at Sandeman Hospital Quetta. Period: January 2017 to June 2018. Material \& Methods: Randomized controlled study designed for comparison was carried out. Total 86 patients of both gender had grade III and IV hemorrhoids were enrolled and randomly divided in two groups. LigaSure group and Conventional group. After obtained institutional permission and informed consent all patients were prepared for surgery as per unit protocol. Patients of both groups were evaluated for operative time, per operative bleeding, post-operative pain, hospital stay, wound healing time, and time return to work. Data collected and analyzed on SPSS version 20. Results: Total 86 patients enrolled for study 58 (66.4\%) males and 28 (32.6\%) females, age range 22-76 years. Patients randomly divided in LigaSure and conventional groups (43 in each group). Operative time and per operative bleeding was significantly less in LigaSure group as compared to conventional (P-Value, 0.001). Post-operative complications like pain and urine retention ware significantly less in LigaSure group (P-Value $<0.001)$. Hospital stay, Healing time and return to routine life were significantly early in LigaSure group ( $p$-Value $<0.001$ ). Conclusion: LigaSure sealing and cutting system is safe and effective tool in Milligan \& Morgan Haemorrhoidectomy.

Key words: Haemorrhoidectomy, Haemorrhoids, LigaSure, Milligan \& Morgan.

Article Citation: Ahmed M, Mehboob M, Ahmed F, Javeed S, Khan A, Qureshi SA. LigaSure vessel sealing system versus conventional tools in Milligan and Morgan Haemorrhoidectomy: A Randomized control trial. Professional Med J 2020; 27(4):746-751. DOI: 10.29309/TPMJ/2020.27.04.3658

\section{INTRODUCTION}

Haemorrhoids are normal vascular cushions of anal canal if symptomatic (Bleeding, itching or prolapsed) called haemorrhoidal disease or symptomatic heamorrhoids. ${ }^{1}$ Surgical treatment is haemorrhiodectomy and based on excision and ligation of pedicle of these cushions was first introduced in 1939 by Milligan and Morgan² since then it is most popular and considered gold standard for the treatment of symptomatic grade III and IV haemorrhoids. ${ }^{3}$ Because of its painful nature surgeons trying to modify or search an alternate technique to reduce the pain. Two decades latter Furguson introduced his own closed technique on the bases of same principles of Milligan \& Morgan and claimed it is less painful. In both conventional techniques haemorrhoidal cushion is excised by using sharps or diathermy and pedicle is legated and defect is either left open as in Milligan \& Morgan or closed as in Furguson. Surgeons throughout the world are continually trying to find alternate procedures to decrease pain and other complications but none of the newly adopted technique including Haemorrhoidopexy, Haemorrhoidal Artery ligation (HLA) with or without recto-anal repair (HLA-RAR) had shown to be significantly helpful. ${ }^{2}$

LigaSure a new bipolar device which has property to effectively seal and cut the vessels and tissues with minimal spread of tissue injury $(0.2 \mathrm{~mm})$ and effective in sealing of vessels up to diameter of $7 \mathrm{~mm}^{3}$ hence fewer trauma and less anal spasm leads to less pain as compare to conventional methods. LigaSure haemorrhoidectomy is not a new or alternate procedure but it is a new and 
advanced tool used in Milligan and Morgan haemorrhoidectomy. In world literature several studies proved efficacy and safety of LigaSure with encouraging results ${ }^{4,5,6,7}$ but in our region (Pakistan) very little work has done and only one study conducted with convincing results. ${ }^{8}$ Using LigaSure the principles of surgery are essentially the same (excision of haemorrhoidal cushions and suture less sealing of its pedicle) but with minimal tissue damage. In present study we evaluated the use of LigaSure in Milligan and Morgan haemorrhoidectomy in terms of operative time, per operative bleeding, post operative pain, hospital stay and return to routine life and compared it with use of conventional too Is.

\section{METHODOLOGY}

This study was conducted in the Department of Surgery Bolan University of Medical \& Health sciences at Sandman Provincial Hospital Quetta, from $1^{\text {st }}$ January 2017 to $30^{\text {th }}$ June 2018. After institutional permission obtained from head of institution and informed consent patients were enrolled for study.

Per calculated sample size total 86 patients of both gender (58 males and 28 females) were included in the study. Inclusion criteria were patients having symptomatic grade III and IV haemorrhoids admitted through OPD and gave informed consent. Exclusion criteria were, patients with symptomatic haemorrhoids secondary to Liver disease, needed additional procedure i.e. associated with anal fistula or fissure and those having other co-morbid conditions. Pre-operative work up and patients preparation for surgery done as per unit protocol. Patients were randomly divided in two groups, $43(50 \%)$ in LigaSure group and $43(50 \%)$ in conventional group. Conventional group were selected for excision of haemorrhoidal cushions by conventional tools i.e. diathermy or scissors and transfixation and ligation of its pedicle with absorbable sutures. In LigaSure group, we used LigaSure sealing and cutting system for excision of cushions and suture less sealing of its pedicle. All patients were operated by surgeons having equal qualification and experience or by senior residents under their direct supervision. Patients were observed per operative for time duration and bleeding and post operatively for pain, needs of analgesia, urinary retention, reactionary bleeding and hospital stay. After discharge from ward all patients prescribed oral analgesia (Paracetamol) and laxatives and called for follow up at one week, three weeks and after 6 months. Patients were assessed for pain, wound healing (defined by appearance of granulation tissue), return to work and anal stenosis. Observed data saved in pre designed Performa sheet and at the end of study all data entered in SPSS software and analyzed. For comparison of both groups Chi -Square test applied and result obtained.

\section{RESULT}

The age range from 22-76 years, mean $46.65 \pm$ 12.81 years. There were 58 males $(64.4 \%)$ and 28 females (32.6\%). Male to female ratio was 2.07:1. Patients were randomly divided in two groups LigaSure group and conventional group. Each group comprises 43(50\%) patients. Majority of patients (87.2\%) were between 31 to 70 years of age. Majority $53(61.6 \%)$ patients had grade IV haemorrhoids. There was no significant difference in age, gender and haemorrhoidal grades in both groups. Table-l.

The operative time was significantly lower in LigaSure group. Majority of patients 35/43 (81.39\%) in LigaSure Group took less than 10 minutes mean $1.18 \pm .39$ range $<10-15$ minutes, while in conventional group majority patients took $15-25$ minutes or more mean $2.02 \pm 0.7$ range 10- $>25$ minutes (P-Value $<0.001$ ). Per operative bleeding in LigaSure Group was less mean 11.27 \pm 2.91 range $8-20 \mathrm{ml}$ as compare to conventional group where mean was $30 \pm 13.6$ range $10-60$ $\mathrm{ml}$ (P-Value 0.001). Moreover need of anal pack in conventional group was compulsory while in LigaSure group few patients required anal packing. Regarding postoperative complication $20(46.51 \%)$ patients developed urinary retention in conventional group while $8(18.60 \%)$ patients got urinary retention in LigaSure group. No post operative bleeding observed in either group.

Majority of Patients in LigaSure had experienced 
mild to moderate pain on Visual Analog Score (VAS) in immediate post operative period and on day one. On day 1 mean VAS was $1.48 \pm 0.58$ while on day 2 mean VAS was $1.16 \pm 0.37$. Almost all patients were pain free on day seven mean VAS score was $0.16 \pm 0.43$. In conventional group majority patients had moderate to severe pain score on day 1 mean $2.37 \pm 0.48$ and on day 2 mean score was $2.02 \pm 0.63$. On day seven mean VAS was $1.00 \pm 0.57$ ( $p$-value <0.001). Hospital stay was less in LigaSure group majority patients $33 / 43(76.74 \%)$ discharge on day one (mean1.34 \pm 0.71 days) while in conventional group $25(58.13 \%)$ patients was able to discharge on $3^{\text {rd }}$ day and 6 patients stayed 4-7 days (mean $1.9 \pm$ 0.70 days) in hospital (P-value $<0.001$ ). Healing time was significantly earlier in LigaSure group as compare to conventional group. In LigaSure group majority of patients 36 out of 43 (83.7\%) resumed their work in one week after discharge (mean $1.2 \pm 0.51$ weeks) while in conventional group only 7 patients resumed routine work in one week majority patients of conventional group resumed work after 3-5 weeks (mean $2.13 \pm$ 0.67 weeks) (P-value <0.001). Table-II. One case of stenosis was reported in conventional group while none in LigaSure group. No recurrence was reported in either group during follow up period.

\begin{tabular}{|c|c|c|c|c|c|c|c|c|c|}
\hline Patient Variable & \multicolumn{4}{|c|}{ LigaSure Group } & \multicolumn{4}{|c|}{ Conventional Group } & P-Value \\
\hline \multirow{2}{*}{$\begin{array}{l}\text { Age group } \\
\# \text { of Patients }\end{array}$} & $22-30$ & $31-50$ & $51-70$ & $71+$ & $22-30$ & $31-50$ & $51-70$ & $70+$ & \multirow{2}{*}{0.134} \\
\hline & 6 & 21 & 13 & 3 & 1 & 28 & 13 & 1 & \\
\hline \multirow{2}{*}{$\begin{array}{l}\text { Gender } \\
\text { \# of Patients }\end{array}$} & \multicolumn{2}{|c|}{ Male } & \multicolumn{2}{|c|}{ Female } & \multicolumn{2}{|c|}{ Male } & \multicolumn{2}{|c|}{ Female } & \multirow{2}{*}{0.818} \\
\hline & \multicolumn{2}{|c|}{30} & \multicolumn{2}{|c|}{13} & \multicolumn{2}{|c|}{28} & \multicolumn{2}{|c|}{15} & \\
\hline $\begin{array}{l}\text { Haemorrhoids grade } \\
\text { \# of Patients }\end{array}$ & \multicolumn{2}{|c|}{ Grade III } & \multicolumn{2}{|c|}{ Grade IV } & \multicolumn{2}{|c|}{ Grade III } & \multicolumn{2}{|c|}{ Grade IV } & 0.092 \\
\hline
\end{tabular}

\begin{tabular}{|l|c|c|c|}
\hline \multicolumn{1}{|c|}{ Variables } & LigaSure group & Conventional group & P-Value \\
\hline Operative time & Range 10-15 minutes & Range 10->25 minutes & 0.000 \\
\hline Per operative Bleeding & Mean $11.27+2.97$ & Mean $30+13.36$ & 0.000 \\
\hline Pain score on Day One & Mean1.41+.58 & Mean $2.37+.48$ & 0.000 \\
\hline Pain Score on Day Two & Mean $1.16+.37$ & Mean $2.02+.63$ & 0.000 \\
\hline Pain Score on Day Seven & Mean $0.16+.43$ & Mean $1.00+.75$ & 0.000 \\
\hline Hospital Stay (days) & Mean $1.34+.71$ & Mean $1.93+.70$ & 0.000 \\
\hline Return to work (weeks) & Mean 1.20 +.51 & Mean $2.13+.67$ & 0.000 \\
\hline
\end{tabular}

\section{DISCUSSION}

Standard surgical treatment of symptomatic haemorrhoids based on principles of excision and ligation of anal cushions introduced by Milligan and Morgan in $1937 .{ }^{9}$ Surgery generally recommended for grade III and IV haemorrhoids and Milligan and Morgan procedure is the most popular technique among surgeons all over the world but remains unpopular among general population because of its painful nature. ${ }^{1}$ Furguson introduced a closed technique in 1959 and claimed that the procedure reduces the pain. ${ }^{10}$ Both techniques having similar possible complications and outcomes in terms of pain, bleeding, and prolong hospital stay. Because of this researchers looking for optimal alternatives for treatment such as Haemorrhoidopexy, haemorrhoidal artery ligation with or without recto-anal repair (HLA-RAR). ${ }^{2}$ In recent years new tools and devices are being used to overcome these complications such as harmonic scalpel and LigaSure sealing system. ${ }^{11,12,13}$ Use of LigaSure in Milligan and Morgan haemorrhiodectomy seems to be safer and has less pain and other complications as compare with recent or conventional tools. ${ }^{5,6,14,15}$ Despite clear advantages of newer tools such as LigaSure reported in literature ${ }^{5,6,14,15}$ surgeons continue to 
prefer traditional sharps and diathermy because newer tools are costly and not available in every institution especially in developing countries like Pakistan. ${ }^{8}$ Moreover, studies have not yet standardized the significant effectiveness and long-term results. ${ }^{1,6,8}$

In present study we concluded that use of LigaSure in haemorrhoidectomy has statically significant clear advantages over conventional tools in terms of operative time, bleeding, post operative pain, hospital stay, and return to work. In our study we observed significant lower operative time in LigaSure group as compare to conventional group ( $<10$ minutes VS 15 to $>25$ minutes P-value $<0.001)$. In a study by Wagih $M G{ }^{14}$ the mean operative time in LigaSure was significantly low (11.22 VS 28.42 minutes) as compare to diathermy (P-Value $<0.0001)$. In a study conducted by Ghimire $P$ et $\mathrm{al}^{16}$ mean operative time in LigaSure group was $7.6 \mathrm{~min}$ ( $\pm S D 2.5)$ and in conventional group it was 18.9 min ( $\pm S D$ 4.5). Similarly in other studies significantly less operative time was observed. In a study conducted by Islam M T et $\mathrm{al}^{17}$ mean operative time was 7.7 VS 18.2 minutes, Talha A et $\mathrm{al}^{18}$ observed less operative time in LigaSure and Harmonic Scalpel groups as compare to diathermy group $\{8$ VS 18 minutes $(P<0.001)$ \}. Nienhuijs and de hung ${ }^{4}$ in a Meta analysis concluded from 12 studies on 1142 patients that use of LigaSure in heamorrhoids surgery was less painful and without adverse effect or any other complication. In our study we found that LigaSure is effective tool in Milligan and Morgan procedure in terms of pain. In present study the majority patients in LigaSure group score less on VAS on day 1, 2 and 7 (P-Value <0.001). In a study conducted by Khanna $R$ et al $^{19}$ observed less VAS pain scores in patients of LigaSure group on day 0,1 and7 compared with the Furguson's closed haemorrhoidectomy(P-value <0.001). Similarly Bakhtiar $\mathrm{N}$ et $\mathrm{al}^{8}$, Ghimire $\mathrm{P}$ et $\mathrm{al}^{16}$ and Islam MT et $\mathrm{al}^{17}$ also observed less pain in LigaSure group.

Use of LigaSure in haemorrhoidectomy results less peroperative bleeding as compared to open (M\&M) or closed (furguson) haemorrhoidectomies. ${ }^{20}$ In present study we observed less per operative bleeding in majority patients of LigaSure group $(8-15 \mathrm{ml})$ while in conventional group majority patients bleed more than $25 \mathrm{ml}$. Similarly in other studies significantly less per operative bleeding was observed ${ }^{5,19}$ which is consistent with our study. In Studies conducted by Haksal CM et $\mathrm{al}^{13}$ and Ghimire $\mathrm{P}$ et $\mathrm{al}^{16}$ the hospital stay was significantly lower in LigaSure group. Similarly we observed that hospital stay in present study was significantly less in LigaSure group as compare to conventional group. In LigaSure group 33 out of $43(76.74 \%)$ patients were able to discharge on day 1 while in conventional group $25.58 \%$ (11/43) patients were discharged. In our series majority $(83.72 \%)$ patients in LigaSure group returned their routine life in one week and (16.27\%) returned work in 2-5 weeks while in conventional group (83.72\%) patients resumed their work in 2-5 weeks.

Majority of studies conducted on short term benefits of LigaSure ${ }^{5,6,8,12,13}$ while for long term benefits (recurrence and stenosis) patients needs prolong follow up on large scale studies that is possible in case of multi institutional cohort studies. Noori IF $^{6}$ followed his patients little longer time for late complications and found less stenosis in LigaSure group 6.25\% as compared to $10.4 \%$ of conventional group and Haksal MC et $\mathrm{al}^{13}$ found $2.7 \%$ stenosis in LigaSure group. Chen, $\mathrm{CW}$ and et $\mathrm{al}^{15}$ found low recurrence in LigaSure group. In present study we followed our patients for 6 months there was no recurrence or stenosis in LigaSure group while only one stenosis in conventional group.

\section{CONCLUSION}

Use of LigaSure cutting and sealing system in Haemorrhoidectomy is safe and effective and has significantly low complications compared with conventional methods. LigaSure was also associated with faster wound healing.

\section{RECOMMENDATIONS}

1. Our study was conducted in a single institute and requires more extensive study involving multi institutional approach for better analysis.

2. A more extensive and long-term monitoring is required for long term complications. 


\section{Conflict of Interest}

We have no conflict of interest.

Copyright@ 05 Aug, 2019.

\section{REFERENCES}

1. KeracaAS.994cases ofFurgusonhaemorrhoidectomy: 10 years experience of a single surgeon. $\mathrm{J}$ Clin Anal Med 2017; 8(4) 307-310.

2. Chen JC, You JF, Current status of surgical treatment for haemorrhoids- systemic review and Meta analysis. Chang Gung Med J; 2010, 33(5). 488-500.

3. Maurizio Gentile, Michele De Rosa, Gabriele Carbone, Vincenzo Pilone, Francesca Mosella, and Pietro Forestieri, "LigaSure haemorrhoidectomy versus conventional diathermy for IV-Degree haemorrhoids: Is It the Treatment of Choice? A Randomized, Clinical Trial," ISRN Gastroenterology, vol. 2011, Article ID 467258, 6 pages.

4. Nienhuijs SW, de Hungh $\mathrm{IH}$. "Conventional versus LigaSure haemorrhoidectomy for patients with symptomatic haemorrhoids" Cochrane data base system review, Int J Surg 2010; 8(4), 269-273.

5. Emile K Ton, Julie Cornish Ara W. Darzi et all "Meta analysis of short outcomes of randomized control trials of LigaSure Versus Conventional haemorrhoidectmy" arch Surg 2007; 142(12); 12091218.

6. Noori IF, "LigaSure haemorrhoidectomy versus diathermy haemorrhoidectomy for all symptomatic haemorrhoids" Med J Basyla 2018; 15, 83-88.

7. Ahire MD, Rathod CM, Baghadia S, Nandu B. Comprision study between vassel sealing technique and conventional Milligan and Morgan haemorrhoidectomy. Int J Surg; 20163 18844-1849.

8. Bakhtiar N, Moosa FA, Jaleel F, Qureshi NA, Jawaid M. Comparison of haemorrhoidectomy by LigaSure with conventional Milligan Morgan's haemorrhoidectomy. Pak J Med Sci. 2016; 32(3):657-661.

9. E.T.C. Milligan, C. Nounton Morgan, L. Jone, R. Officer "Surgical anatomy of the anal canal and the operative treatment of haemorrhoids" The Lancet, vol 230 No 5959, 1937, Pp1119-1124.

10. Furguson JA and Heaton $J$ R "Closed Haemorrhoidectomy" dis Colon Rectum, 1959, 2, 176179.
11. Sakr M, Saed K, Recent advances in management of haemorrhoids. World J Surg Proced. 2014; 4(3):55-65.

12. Shoukat $H$, lqbal $M$, Shafqatullah et all 'Comparison of haemorrhoidectomy using bipolar diathermy versus Harmonic scalpel" PJHMS vol 10; 2 Apr-Jun 2016; 489-491.

13. Haksal MC, Çiftci A, Tiryaki Ç, Yazıcıoğlu MB, Özyıldız M, Yıldız SY. Comparison of the reliability and efficacy of LigaSure haemorrhoidectomy and a conventional Milligan-Morgan haemorrhoidectomy in the surgical treatment of grade 3 and 4 hemorrhoids. Turk J Surg. 2017; 33(4):233-236.

14. Wagih Mommtaz Ghnnam. Prospective randomized controlled trial of LigaSure versus conventional haemorrhoidectomy for grade III and IV hemorrhoids. Int J Surg Med; 2017; 3(1) 8-13.

15. Chen CW, Lai CW, Chung YJ et all "result of 666 patients treated By LigaSure for symptomatic haemorrhoids" Surgery 2013; Feb 153 (2) 211-218.

16. Ghimire P, Gurung NV, Upadhaya PK, Shrestha S, Gurung A, Poudel SR. Sutureless haemorrhoidectomy Vs open hemorrhoidectomy: A prospective study in a Regional Hospital of Western Nepal; NJMS 3 (2) July-December 2014; 121-123.

17. Islam, M. T., Rahman, M. H., Rahman, M. M., Ahmed, S., \& Begum, N. (2015). Randomized Clinical Trial of LigaSure Haemorrhoidectomy versus Open Diathermy Haemorrhoidectomy. Journal of Armed Forces Medical College, Bangladesh, 10(2), 15-20.

18. Talha A, Bessa $S$, Wahab M. LigaSure harmonic scalpel versus conventional diathermy in excisional haemorrhoidectomy; A randomized control trial; ANZ J Surg 2017 Apr 87 (4); 252-256.)

19. Khanna R, Khanna S, Bhadani S, Singh S, Khanna AK. Comparison of LigaSure Hemorrhoidectomy with Conventional Ferguson's Hemorrhoidectomy. Indian J Surg. 2010; 72(4):294-297.

20. Simillis C, Thoukididou SN, Slesser AA, Rasheed S, Tan E, Tekkis PP. Systematic review and network meta-analysis comparing clinical outcomes and effectiveness of surgical treatments for haemorrhoids. Br J Surg 2015 Dec; 102(13):1603-18. 


\begin{tabular}{|c|c|c|c|}
\hline \multicolumn{4}{|c|}{ AUTHORSHIP AND CONTRIBUTION DECLARATION } \\
\hline Sr. \# & Author(s) Full Name & Contribution to the paper & Author(s) Signature \\
\hline 1 & Manzoor Ahmed & $\begin{array}{l}\text { Concept, data collection, } \\
\text { manuscript writing, data analysis } \\
\text { and references collection. }\end{array}$ & \\
\hline 2 & Mukhtar Mehboob & $\begin{array}{l}\text { Concept, data collection, } \\
\text { manuscript writing and data } \\
\text { analysis, Final review and } \\
\text { approval. }\end{array}$ & \\
\hline 3 & Fida Ahmed & $\begin{array}{l}\text { Data collection, manuscript } \\
\text { writing and data analysis. }\end{array}$ & \\
\hline 4 & Saleem Javeed & $\begin{array}{l}\text { Data collection, References } \\
\text { search data collection. }\end{array}$ & \\
\hline 5 & Abdullah Khan & Concept, data collection. & \\
\hline 6 & Shoaib Ahmed Qureshi & $\begin{array}{l}\text { Concept, data collection, } \\
\text { manuscript writing and data, } \\
\text { Final review and approval. }\end{array}$ & ent. \\
\hline
\end{tabular}

